\title{
Waste Management Strategies in Textile \& Garment Sector
}

\author{
Gupta Khusbu Kumari
}

Army Institute of Fashion and Design, AssistantProfessor, Fashion Design, Kothanur Post,Nagareshwara, Nagenahalli, Bengaluru, Karnataka 560077

\section{To Cite this Article}

Gupta Khusbu Kumari, "Waste Management Strategies in Textile \& Garment Sector", International Journal for Modern Trends in Science and Technology, 6(9S): 58-60, 2020.

\section{Article Info}

Received on 25-August-2020, Revised on 08-September-2020, Accepted on 12-September-2020, Published on 18-September-2020.

\section{ABSTRACT}

Textiles and Apparel (T\&A) sector is one of the most significant industrial sectors and plays a major role towards contribution to national economy, employment generation and exports in developing countriesand most essential consumer goods industry. However, textile industry is accused of being one of the most polluting industries. Not only production but consumption of textiles also produces waste. To counter the problem, textile industry has taken many measures for reducing its negative contribution towards environment. One of such measures is textile recycling- the reuse as well as reproduction of fibers from textile waste. Recycling can be done through thermal, material, chemical and mechanical processes. Textile recycling is beneficial for environmental and economic conditions, reducing demand for textile chemicals, requirement of landfill space is reduced, consumption of less energy and reducing of water wastage. Market research, and efforts are needed to increase consumer awareness and to encourage manufacturers to increase the use of recycled textile waste into new products. Fashion consumption and sustainability are often opposing ideas. Fashion consumption is a highly resource-intensive, wasteful practice; and sustainability frowns on wasteful consumption. Sustainability in the fashion business is still an emerging agenda, not yet established, and many authors have recognised the importance of investigating how sustainability could be achieved

Keywords: Fibers, recycled, textile and waste

\section{INTRODUCTION}

Textiles are manufactured to perform a wide range of functions and are made up of different types of fibers mixed in varying proportions. The textile recycling industry is one of the oldest and most established recycling industries in the world. While the textile industry has a long history of being thrifty with its resources, a large proportion of unnecessary waste is still produced each year. Commercially, textile waste generation is influenced by the production of textile goods, higher the production, the greater the amount of waste. The textile industry has a very negative impact on our environment. Clothing manufacturing generates large amounts of textile waste, which ends up in landfills. Only a minute amount is re-utilized. Out of various activities in textile industry, chemical processing contributes to about $70 \%$ of pollution. (1)

\section{BACKGROUND LITERATURE}

Like all wastes, textile waste originates from the community via number of streams including the fibers, textile or clothing manufacturing industries, consumers, commercial and service industries. Majority of textile waste comes from household 
sources. Average lifetime of any clothing is deemed to be for about 3 years, after which, they are thrown away as old clothes. Sometimes even 'not so worn garments' are also discarded as they become unfashionable, or undesirable. These are post-consumer waste that goes to jumble sales and charitable organizations. (2)

Pre-consumer textile waste Pre-consumer textile waste is the manufacturing waste that is generated by processing fibers and the production of finished yarns and textiles, technical textiles, nonwovens, garments including off-cuts, selvages, rejected material, etc. This waste is generally clean waste.

Post-consumer textile waste Post-consumer textile waste consists of any type of garments or household textiles that the consumer no longer needs because they are worn out, damaged, or have gone out of fashion. This category has been of reasonable to good quality garment that can be recovered and subsequently recycled by another user as second-hand clothing, much of which is sold to third-world nations like Togo, Ethiopia, Comoros, Haiti etc.

Industrial textile waste Industrial textile waste is generated from commercial and industrial textile applications including commercial waste such as carpets and curtains. This waste is generally "dirty waste". A substantial proportion of these end-of-life goods are incinerated or dumped to landfills. (3)

\section{STRATEGIES}

Sustainable waste management system "incorporatesfeedback loops, is focused on processes, embodies adoptability and diverts wastes from landfill".Moreover, a sustainable waste management strategy must consider the sustainable developmentobjectives, i.e. environmental consequences, economic aspects and social issues. The most widely known sustainable waste managementstrategy in the fashion industry is referred to as the 3Rs, the waste hierarchy: Reduce, Reuseand Recycle. However, with the rapid increase of fashion purchases and subsequent disposals, finding alternative solutions to managing waste is becoming an important issue. The refashioningof old clothes recently emerged as an alternative strategy for fashion waste management. (4)

This paper evaluates reusing, recycling and refashioning as three sustainable waste managementstrategies for the fashion industry and refers to the following definitions:
Reusing-The product is used again for the same purpose, sometimes with re-distributionand resale.

Recycling- A process of materials being shredded or pulled apart into small fractions orfibres, called shoddy or mungo. Recovered fibres from used textiles are mixed with virginfibres to produce new fabrics or used to produce other products such as industrial filling, sound insulation panels or carpets.

Refashioning- A process that intercepts discarded clothing, reclaims, re-cuts and refashions,

returning the item to the clothing stream, effectively creating a new loop and postponingits grave ending

Zero waste-A Zero waste strategy will lead to faster innovation and movement far beyond incremental approaches that don't include an end point goal. The zero-waste strategy leads us to look for inefficiencies in the use of materials, energy and human resources.

To achieve a sustainable future, extreme efficiency in the use of all resource will be required in order to meet the needs of all of the world's inhabitants. A zero-waste strategy directly supports this requirement. The zero waste strategies have been adopted by large and small business and by both foreign and domestic governments. (5)

\section{ENVIRONMENTAL AND ECONOMIC BENEFITS OF GARMENT RECYCLING}

Garment recycling have essential benefits in terms of environmental as well as economical. Some are mentioned below: Reduces the need for landfill space.

- Reduces pressure on virgin resources.

- Aids the balance of payments as we import fewer materials for our needs, which causes less pollution and energy savings, as fibers do not be transported from abroad.

Benefits of reclaiming fiber Savings

\section{CONCLUSIONS}

A large amount of textile waste is disposed of in landfills each year. That not only poses economic and environmental problems to the society but also represents a severe waste of resources. Market research and efforts are needed to increase consumer awareness and to encourage manufacturers to increase their use of recycled 
textile waste into new products. People those are impetuous for waste disposal would think rationally about the rejuvenation of waste fibers for raise the profit for their firm and also it reflects noble cause for society by reducing the contamination in environment. Textiles in India are recycled both for the domestic and the global market. In the domestic market recycled textile products are generally found in the form of floor mats, wipes and rugs. The fibres extracted during recycling of clothing are converted into recycled yarns and it is used in different textile products and also as fillers. Textile recycling also teaches everyone to reuse, reduce and recycle these products instead of throwing them away. So, it is the time to think and make up our mind to use recycled products to reduce the environmental pollution.

\section{REFERENCE}

[1] Wang Y. Fiber and Textile Waste Utilization. Waste Biomass Valor, 2010; 1:135-143.

[2] Anonymous. SMART textile recycling checklist for communities, 2015. http://www.smartasn.org/ textile recycle/ Retrieved on 07.10.2015.

[3] Chavan RB. Environmental Sustainability through Textile Recycling. Journal of Textile Science \& Engineering, 2014.

[4] Anonymous. Textile recycling, 2015. https://en. wikipedia.org/wiki/Textile recycling. Retrieved on 02.07.2015

[5] Textile recycling, 2015. https://en. wikipedia.org/wiki/Textile recycling. Retrieved on 02.07.2015

[6] Reducing costs through waste management guide: the garment and household textiles sector, june 1997

(n)
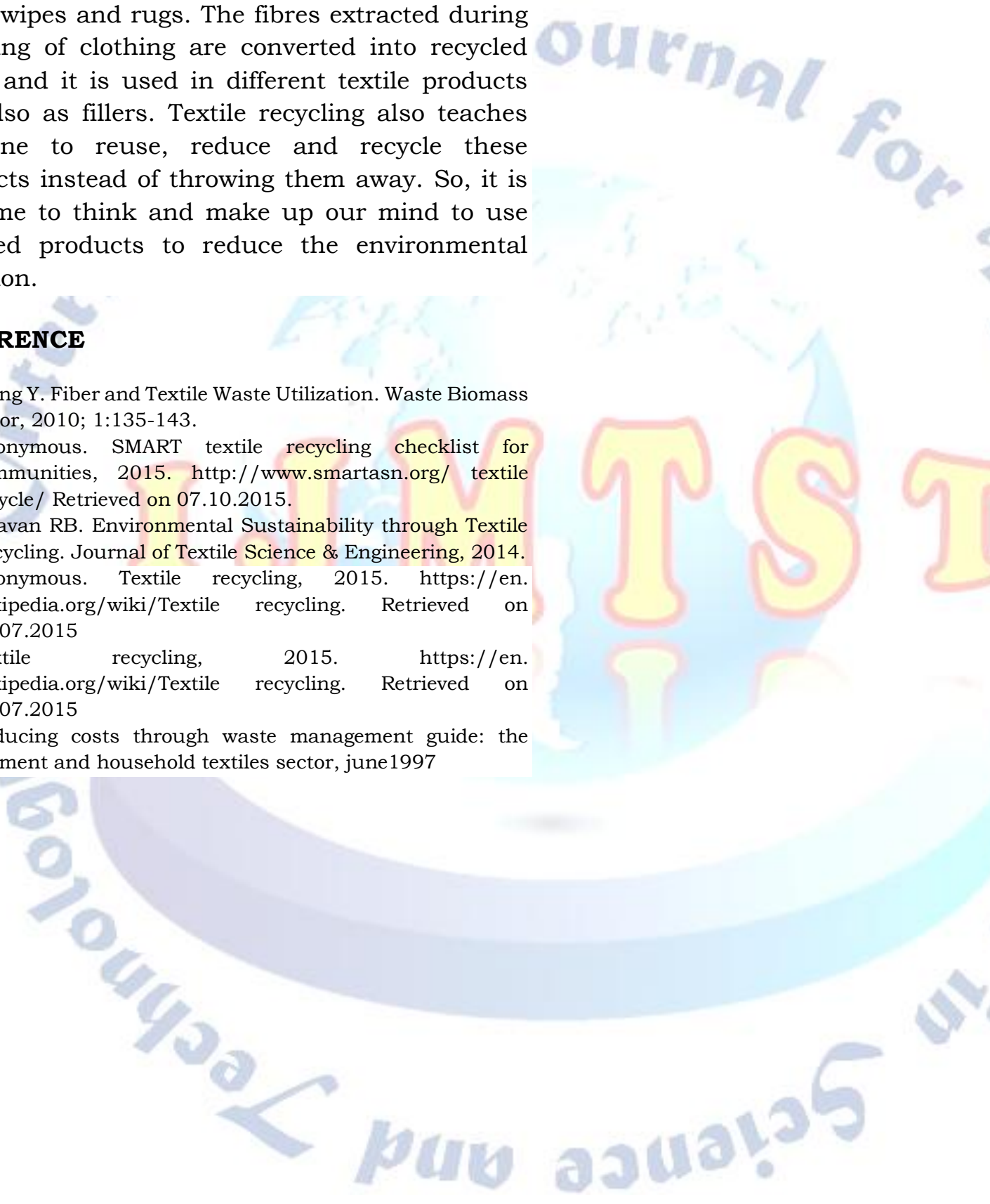